\title{
A comparative study of the nutritional and physiological significance of raw and heated soya beans in chicks and goslings
}

\author{
BY ZAFRIRA NITSAN* \\ Division of Poultry Science, Agricultural Research Organization, \\ The Volcani Center, Rehovot, Israel \\ AND I. NIR \\ Department of Animal Science, The Hebrew University of ferusalem, \\ Faculty of Agriculture, Rehovot, Israel \\ (Received 8 January 1976 - Accepted 23 July 1976)
}

\begin{abstract}
I. The comparative effects of raw soya beans on food intake, growth, digestive organ weight, and enzyme activities in goslings and chicks were studied.

2. Goslings were more affected than chicks by the ingestion of a raw soya-bean diet (RSD) in the following ways : reduction in food intake and growth rate; increase in relative weight of the digestive organs; reduction in specific activities of lipase $\left(E C_{3} .1 .1 .3\right)$, amylase $\left(E C_{3} .2 .1\right.$. I) and chymotrypsin (EC 3.4 .4 .5 ) in the pancreas (not affected in chicks); greater inhibition of trypsin (EC $3.4 \cdot 4.4)$, chymotrypsin and amylase in the intestinal contents of goslings than of chicks.

3. Addition of methionine to the RSD improved food intake and growth rate more in goslings than in chicks.

4. The interrelationships between enzyme activities, food passage rate, nutrient absorption and food intake regulation are discussed.
\end{abstract}

In a field experiment carried out on geese, force-fed for the production of fatty liver, the addition of $200 \mathrm{~g}$ soya beans/ $\mathrm{kg}$ to the maize diet markedly depressed, and in some geese even completely blocked, the passage of food through the digestive tract (I. Nir \& M. Perek, unpublished results). In the present work a study was made of whether such an effect is found also when soya beans are given ad lib. The growth rate of goslings is very rapid compared with that of chicks and therefore, they are more sensitive to dietary deficiencies and antinutritional factors. The effects of enzyme inhibitors in soya bean have been widely studied in chicks (Liener \& Kakade, r 969; Rackis, 1974), but to our knowledge no such work with goslings has been reported. The objective of the present work was to conduct a comparative study of chicks and goslings in order to evaluate the effects of the soya bean enzyme inhibitors on growth, food utilization, weight and enzyme activities in the digestive organs, and other physiological responses of the respective species.

* Contribution No. 295-E, 1975 series of the Agricultural Research Organization. 
Table $\mathbf{I}$. Composition of the diets containing raw or heated soya beans given to goslings and chicks*

\begin{tabular}{|c|c|c|c|c|}
\hline \multirow{2}{*}{ Constituents } & \multirow{2}{*}{$(\mathrm{g} / \mathrm{kg})$} & \multicolumn{3}{|c|}{$\begin{array}{l}\text { Chemical composition of the } \\
\text { ground soya beans }(\mathrm{g} / \mathrm{kg})\end{array}$} \\
\hline & & & Raw & Heated \\
\hline w ground soya beanst & 800 & & & \\
\hline trace elements $\ddagger$ & 4 & Dry matter & 913 & $9 r_{4}$ \\
\hline hosphate & 20 & Crude protein & 315 & 312 \\
\hline onate & I 5 & (nitrogen × 6.25) & & \\
\hline ride & 3 & Diethyl ether extract & 173 & 188 \\
\hline & $\begin{array}{l}79 \\
79\end{array}$ & Ash & $4^{8}$ & 49 \\
\hline
\end{tabular}

Heated or raw ground soya beanst

Vitamins and trace elements $\downarrow$

Dicalcium phosphate

Calcium carbonate

Sodium chloride

Cerelose

Maize starch

Chemical composition of the

* The raw and heated soya-bean diets contained $250 \mathrm{~g}$ protein $/ \mathrm{kg}$ and $13.7 \mathrm{MJ}$ metabolizable energy/kg, calculated as described by (US) National Research Council (197I).

$\uparrow$ The heated soya beans contained $28 \%$ of the trypsin-inhibitor activity found in the raw beans when determined by the method of Gertler \& Nitsan (I970).

I As described by Nir, Shapira, Nitsan \& Dror (1974).

\section{EXPERIMENTAL}

\section{Animals and diets}

Twenty one-day-old, cross-bred male New Hampshire $\times$ White Leghorn chicks and twenty goslings from a local breed (Nir \& Perek, I97I) were wing-banded with numbers and kept in groups of ten birds in thermostatically controlled electrically heated batteries with raised wire floors. For the first $2 \mathrm{~d}$, the chicks and the goslings received a commercial chick diet, $220 \mathrm{~g}$ crude protein (nitrogen $\times 6.25$ ) $/ \mathrm{kg}$. On the 3 rd day, each species was divided into two groups of ten, according to body-weight, to receive the experimental diets. The composition of the experimental diets is shown in Table $\mathbf{r}$.

Soya beans were ground before being included in the raw soya-bean diet (RSD). Some of the soya beans were heat-treated as described by Renner \& Hill (r960), before being used for the preparation of the heated soya-bean diet (HSD).

The birds had free access to food and water. The total food intake of each group and the individual body-weights were recorded daily. On the 15 th day of the experiment, each group was divided again into two equal subgroups (five birds each) on the basis of body-weight. The diet of one subgroup of each species was supplemented with $4 \mathrm{~g}$ DL-methionine $/ \mathrm{kg}$. The goslings and the chicks were killed by dislocation of the neck on the 21 st and 22nd days of the experiment, respectively. Before killing the birds, heparinized blood was drawn by heart puncture, and centrifuged, and the plasma was frozen at $-20^{\circ}$. At autopsy the proventriculus, gizzard, small intestine, caecum, colon, pancreas, liver, kidneys, and abdominal adipose tissue were removed. The small intestine and caecum contents were collected and all the organs were weighed. The contents of the small intestine and caecum, the pancreas and liver were frozen at $-20^{\circ}$ for subsequent analysis. The skin with the feathers was undressed and weighed after careful removal of the subcutaneous adipose tissue. 


\section{Chemical analysis}

Plasma total lipids were determined by the method of Zöllner \& Kirsch (1962). Liver lipids were determined gravimetrically after extraction with chloroformmethanol $(2: I, v / v)$.

\section{Determination of enzyme activities}

The pancreases and the intestinal contents of the jejunum, ileum and caecum were prepared for enzyme activity determination as described by Nitsan, Dror, Nir \& Shapira (1974). Trypsin (EC 3.4.4.4) and chymotrypsin (EC 3.4.4.5) activities were measured as described by Nitsan $\&$ Liener (1976), using $N$-benzoyl-DL-arginine$p$-nitroanilide hydrochloride and $N$-glutaryl-L-phenylalanine- $p$-nitroanilide (Sigma, Chemical Co., St Louis, Mo. 63178, USA), respectively, as substrates. Amylase (EC 3.2.1.1) activity was determined according to the method of Bernfeld (1955) with some modifications (Gertler \& Nitsan, 1970). Lipase $(E C$ 3.1.1.3) was determined by the method of Seligman \& Nachlas (rg63), using naphthyl-laurate as substrate. The samples were incubated for ro min at $37^{\circ}$. Enzyme activities were expressed as units of activity, where $I$ unit is defined as an absorbance change of $1 \mathrm{O}^{-3}$ absorbance unit for trypsin and chymotrypsin and $1 \mathrm{O}^{-5}$ for amylase under the conditions specified in each assay system, using $12.7 \mathrm{~mm}$ Bausch \& Lomb test tubes. Lipase units were defined as $\mu \mathrm{g}\left(\times 10^{-2}\right)$ naphthol released/ro min at $37^{\circ}$.

\section{Statistical treatment of results}

The data were subjected to analysis of variance as described by Cochran \& Cox (1957), with separation of means by Duncan's (1955) multiple-range test.

\section{RESULTS}

Food intake, body-weight gain and food conversion efficiency (FCE)

Food intake of the goslings given RSD was considerably depressed $(49 \%$ of the HSD intake), while in the chicks given the RSD only a small difference $(93 \%$ of the HSD intake) was observed (Table 2). Growth inhibition caused by the ingestion of RSD was greater in the goslings than in the chicks ( $7 \mathrm{I}$ and $59 \%$, respectively), when compared with the parallel groups given HSD. Addition of methionine during the

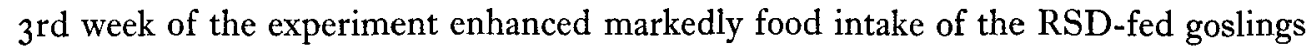
and only slightly in the HSD-fed goslings and the chicks on both diets. The increased food intake was concomitant with an improved growth rate (Table 2). FCE was about $50 \%$ lower in the RSD- than in the HSD-fed groups of both species. Addition of methionine improved FCE by 9 and $39 \%$ in the HSD- and RSD-fed goslings and by 19 and $59 \%$ in the respective groups of chicks.

\section{Organ weights}

Feeding on RSD caused an increase in the relative weights of all the digestive organs in both species (Table 3 ). This effect was more pronounced in the goslings than in 


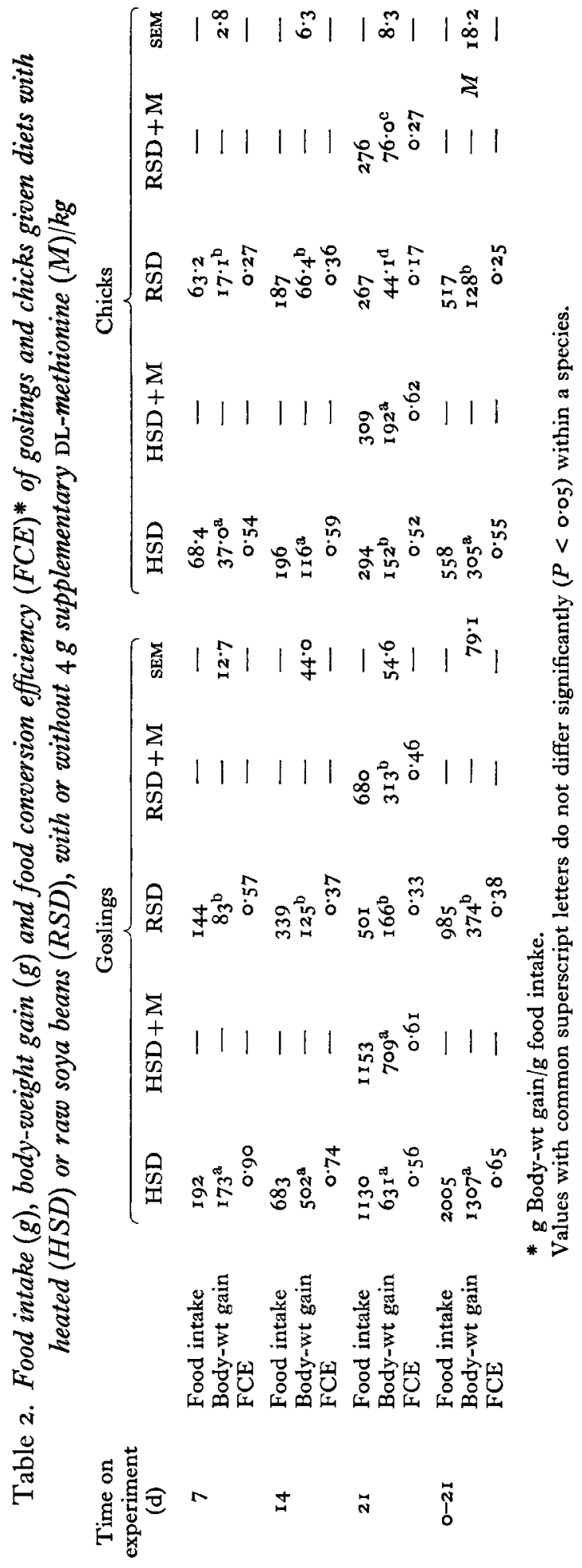


Vol. 37

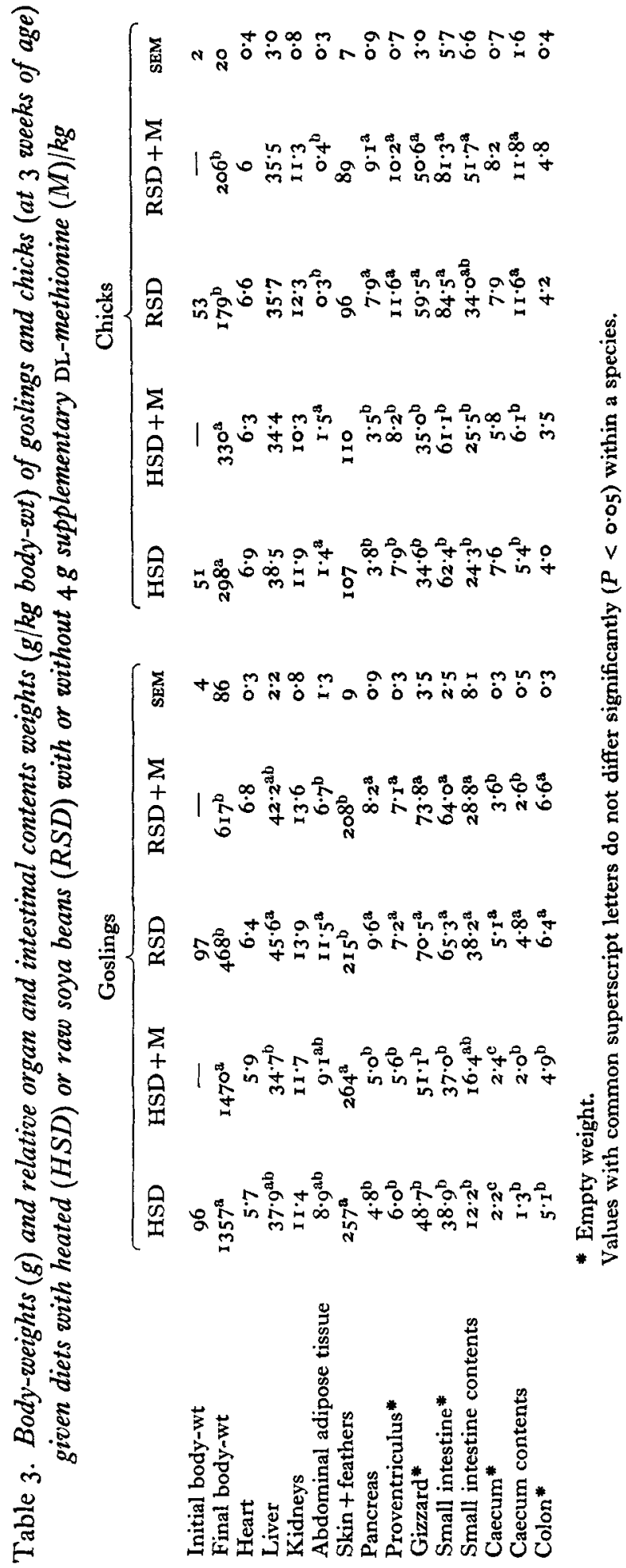


the chicks. The increase in the average relative weights of the small intestine and caecum was about 70 and $90 \%$ in the goslings and 30 and $20 \%$ in the chicks, when compared with the parallel groups given HSD with or without supplemented methionine. The weight of intestinal contents increased parallel with the weight of the small intestine in both species. Pancreas enlargement following RSD ingestion was I.8- and $2 \cdot 3$-fold in the goslings and chicks, respectively. Relative liver weight was $20 \%$ greater in the RSD- than in the HSD-fed goslings. No such effect was noticed in the chicks. Kidney and heart relative weights were not significantly affected by the diet in either species. The relative skin and feather weight, which was much higher in the goslings than in the chicks, was depressed by about $20 \%$ in both species when they were fed on RSD compared with HSD. The relative abdominal adipose tissue weight was somewhat higher (not significantly) in the RSD-fed goslings, while a significant decrease was found in the RSD-fed chicks.

\section{Plasma and liver lipids}

Plasma total lipids were higher in goslings fed RSD compared with HSD: 26. I and $10.1 \mathrm{mg} / \mathrm{ml}$ respectively. No such effect was observed in chicks in which plasma lipid concentration was 5.7 and $6.6 \mathrm{mg} / \mathrm{ml}$ in the RSD- and HSD-fed chicks. No significant differences were noted in liver total lipid concentration of chicks or goslings fed on the different diets (around 55 and $30 \mathrm{mg} / \mathrm{g}$ total lipids in livers of goslings and chicks respectively).

\section{Digestive enzyme activities}

Pancreas. In the chicks, there were no differences between the groups in the specific activities of the enzymes measured. All the enzymes had levels of activity, per kg body-weight, statistically significantly higher in the RSD- than in the HSD-fed groups. In contrast to the chicks, the specific activities of lipase, amylase and chymotrypsin in the goslings were decreased significantly by feeding RSD. The trypsin specific activity was not affected (Table 4 ). When calculated per kg body-weight, the same trend was found for the amylase and chymotrypsin, while the trypsin activity was about twofold greater in the RSD groups than in the HSD ones, and lipase showed no significant differences between the treatments. Supplementation of the diets with methionine had no significant effect on the pancreatic enzymic activities, in most instances.

Intestinal contents. Trypsin activity was inhibited in the jejunum, ileum and caecum of the two species when they were fed on RSD (see Fig. x). The inhibition in the jejunum and the ileum was much more pronounced in the goslings (about 95\%) than in the chicks (about $35 \%$ ). In the caecum, inhibition of trypsin activity was about $50 \%$ in both species. Chymotrypsin was inhibited along the intestinal tract of the goslings but not that of the chicks, where chymotrypsin activity was either the same or even higher (in the caecum) in the RSD-fed chicks compared with the HSD ones.

Amylase activity was lower in the jejunum and ileum and the level did not change in the caecum of goslings given RSD compared with those given HSD. In the chicks, 


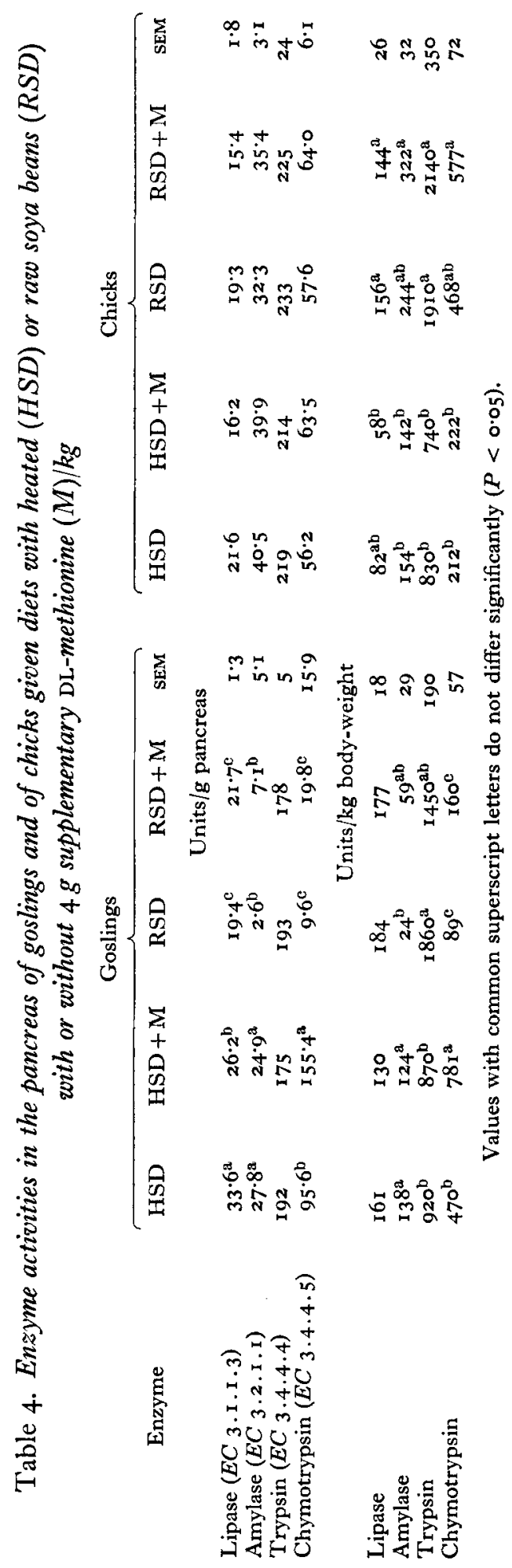




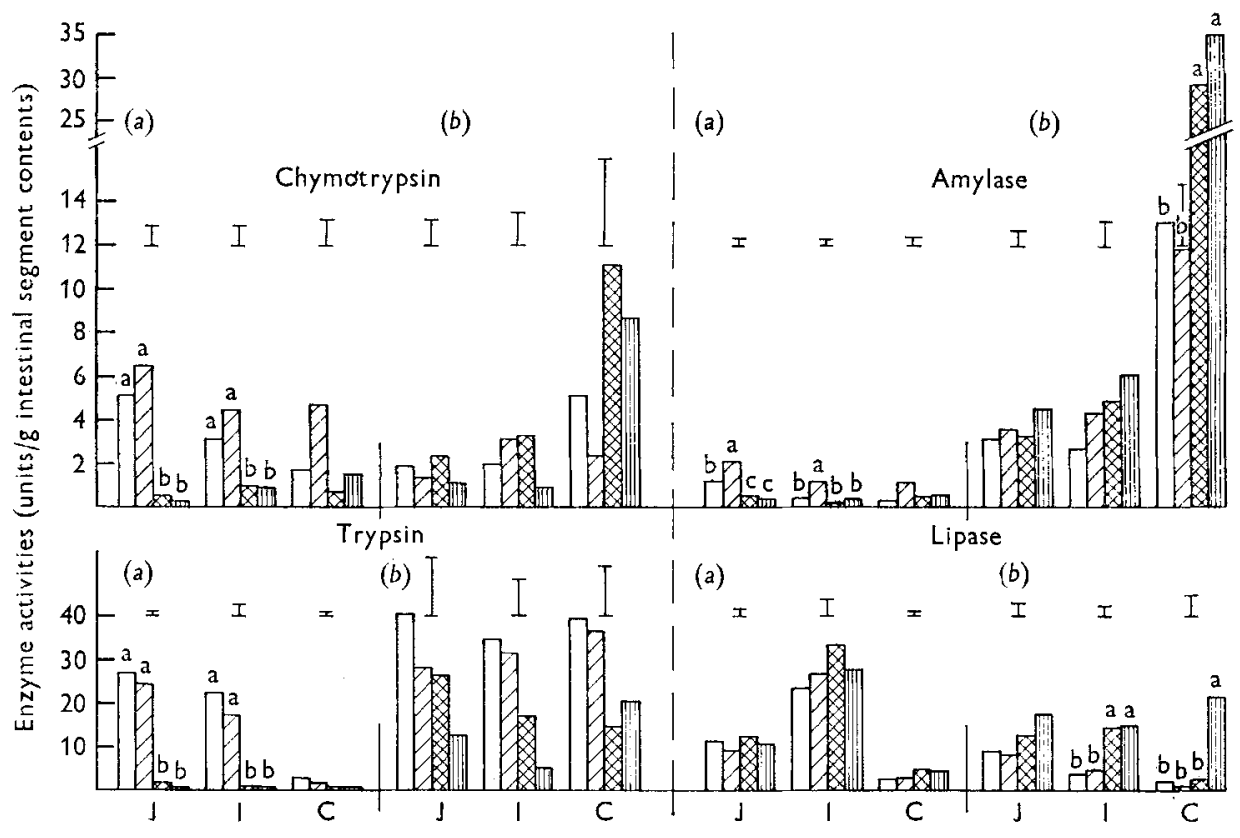

Fig. I. The activities of trypsin ( $E C$ 3.4.4.4), chymotrypsin ( $E C$ 3.4.4.5), lipase ( $E C$ 3.I.I.3) and amylase $\left(E C C_{3} .2 .1 . \mathrm{r}\right) / \mathrm{g}$ intestinal contents in the jejunum (J), ileum (I) and caecum (C) of $(a)$ goslings and $(b)$ chicks given diets with raw (RSD) or heated soya beans (HSD) with and without $4 \mathrm{~g}$ supplementary DL methionine $/ \mathrm{kg}$. Each column represents the mean results for five birds. $\square$, HSD; $\mathbb{Z}$, HSD + methionine; methionine. Vertical bars represent the SE of the treatment means. Values with common superscript letters do not differ significantly $(P<0.05)$.

however, amylase activity was the same in the jejunum and higher in the ileum and caecum of the RSD compared with the HSD group. Feeding RSD increased lipase activity in all the intestinal segments of the chicks. The same trend, but to a lesser extent, was found in the goslings, where the differences between RSD and HSD groups were statistically significant for the caecum only. A species difference was found in the enzyme activities in the intestine. Generally, trypsin and amylase activities were much higher in the chicks than in the goslings, while the opposite was true for the chymotrypsin and lipase activities.

Methionine supplementation during the last week of the experimental period seemed to reduce trypsin and to increase amylase activities on both diets and in both species. Its effect upon the other enzymes was not consistent. The ratio of amylase to the proteolytic enzymes was increased in the small intestine by the addition of methionine to the diets. This increase was more pronounced in the goslings than in the chicks: about 2.5- and 3.5 -fold in the jejunum and ileum of the goslings and $2 \cdot 0-$ and $2 \cdot 2$-fold in the respective segments in chicks. This effect of methionine was not consistent in the pancreas and caecum. 


\section{DISCUSSION}

Goslings were found to be much more sensitive than chicks to the antinutritional factors in raw soya beans. In the present work, most of the growth depression found in chicks can be attributed to decreased FCE and not to lower food intake. In goslings, the more profound growth depression should be attributed to the combined effects of reduced food intake and reduced FCE. When the food intake was calculated per $\mathrm{kg}$ metabolic weight $\left(\mathrm{W}^{0.75}\right)$, it was found that the chicks given RSD ate more (from the 2nd week of the experiment to its end) than those given HSD, while the consumption of the RSD-fed goslings was lower than that of the HSD group during most of the experimental period. These observations on food intake are in accordance with the 'set-point' theory (Lepkovsky, 1973), which claims that appetite is regulated by the amount of adipose tissue in the body. The chicks given RSD had significantly less adipose tissue than those given HSD, and indeed consumed relatively more food. The RSD-fed goslings, which had somewhat more abdominal adipose tissue, consumed less food than those given HSD. Addition of methionine to RSD, which reduced the weight of adipose tissue, increased the food intake per $\mathrm{kg}$ metabolic weight.

The greater sensitivity of goslings to RSD, as compared with chicks, might also be attributed to greater protein and amino acid requirements, due to different body composition and the higher growth rate of the former.

A striking example of differences in body composition of the two species is the relative skin + feathers weight, which was about $\mathbf{2} \cdot 5$-fold greater in the goslings than in the chicks (Table 3 ). The amino acid composition of the proteins of the skin and feathers differs markedly from those of the rest of the carcass (Block, 1956). The RSD-fed goslings had inadequate feathering (from bare skin on the neck and head to thin feathering on the rest of the body), while the feathering of the RSD-fed chicks appeared normal. Feather proteins are very rich in cystine, as compared with muscle or skin proteins (Block, 1956). It seems that the deficiency of sulphur-amino acids, typical of soya-bean protein, was more severe in the RSD-fed goslings than in the RSD-fed chicks. Addition of methionine to the RSD diet improved food intake and growth rate of goslings more than that of chicks, and reduced plasma lipidaemia and adipose tissue weight in the goslings.

The increase in the relative weight of the digestive tract of chicks given RSD, in which the relative food intake exceeded that of the HSD group, is in accordance with an earlier report that the weight of the digestive tract of the chick is parallel to the level of food introduced into the gastrointestinal tract (Nir, Shapira, Nitsan \& Dror, 1974). The above explanation does not hold for the increase in weight of the digestive tract of the RSD-fed goslings, the relative food intake of which was somewhat lower than that of the HSD group. It should be attributed, therefore, to a specific effect of the raw soya beans. Raw soya beans considerably slowed food passage through the stomach of rats (de Muelenaere, 1964) and almost abolished it in force-fed geese (I. Nir \& M. Perek, unpublished results). It seems that slower rate of passage of the food can have the same effect upon the weight of the intestinal tract as increased levels of intake. In both situations the intestinal tract is kept full most of the time, while 
normally the intestinal tract of chicks is almost empty during the night. The higher amount of intestinal contents found in the RSD-fed goslings, the relative food intake of which was lower, is in accordance with the assumption that the RSD slowed food evacuation in this species.

The greater adverse effect of RSD on goslings than on chicks was also reflected in the greater inhibition of trypsin and chymotrypsin and in the lower amylase activity along the digestive tract. In chicks given RSD a very marked inhibition of the proteolytic activity has been reported during the first week which was gradually overcome with age, approaching the activity of the HSD-fed chicks at 4-6 weeks (Alumot 8 Nitsan, 196r). In the present work, in which autopsy took place at the age of $21 \mathrm{~d}$, the chicks given RSD had almost the same chymotrypsin activity as those given HSD and the trypsin inhibition was about $35 \%$. In the goslings, however, the inhibition of the proteolytic enzymes was very marked at this age (Fig. I). This species difference suggests that the process of overcoming protease inhibition in goslings is very slow or nil. Moreover, amylase specific activities, which were lower in goslings than in chicks in the control groups given HSD, were further reduced in the RSD-fed goslings, while in the RSD chicks, amylase activity was either the same or even higher than in the parallel HSD group. The same conclusion can be drawn from the response of the pancreatic enzymes to the ingestion of RSD. While in the chick there was an hypersynthesis of all enzymes measured (enzyme units in the pancreas/kg bodyweight) as was found by others (Liener \& Kakade, r969; Gertler \& Nitsan, I970); in the goslings, only trypsin was over secreted, while chymotrypsin and amylase were markedly depressed.

Although digestive enzymes play a central role in digestion the interrelationships between enzyme activities, food passage rate, nutrient absorption and food intake regulation are poorly understood.

In general, it could be concluded that goslings suffer more than chicks when given raw soya beans. It might be that different nutritional requirements, due to differences in body composition and growth rate potential, accentuated the effects of raw soya beans on the over-all performance found in goslings compared with chicks.

This work was partly supported by the Israel Egg and Poultry Marketing Board and the Israel Ministry of Agriculture.

\section{REFERENCES}

Alumot, E. \& Nitsan, Z. (1961). F. Nutr. 73, 71.

Bernfeld, P. (r955). In Methods in Enzymology [S. B. Colowick and N. O. Kaplan, editors]. New York and London: Academic Press.

Block, R. J. (1956). Amino Acids Handbook. Springfield, Illinois: C. Thomas.

Cochran, W. G. \& Cox, G. M. (1957). Experimental Designs, and ed. New York: John Wiley \& Sons Inc. de Muelenaere, H. J. H. (1964). F. Nutr. 82, 197.

Duncan, D. B. (1955). Biometrics II, 1 .

Gertler, A. \& Nitsan, Z. (1970). Br. F. Nutr. 24, 893.

Lepkovsky, S. (1973). Am. F. clin. Nutr. 26, 271.

Liener, I. E. \& Kakade, M. L. (1969). In Toxic Constituents of Plant Foodstuffs [I. E. Liener, editor]. New York and London: Academic Press.

National Research Council (I97I). Publs natn. Res. Counc., Wash. no. 1345.

Nir, I. \& Perek, M. (197I). Annls Biol. anim. Biochim. Biophys. II, 645. 
Nir, I., Shapira, N., Nitsan, Z. \& Dror, Y. (1974). Br. F. Nutr. 32, 229.

Nitsan, Z., Dror, Y., Nir, I. \& Shapira, N. (1974). Br. F. Nutr. 32, 24 I.

Nitsan, Z. \& Liener, I. E. (1976). F. Nutr. 106, 300.

Rackis, J. J. (1974). F. Am. Oil Chem. Soc. 51, r61 A.

Renner, R. \& Hill, F. W. (1960). F. Nutr. 70, 219.

Seligman, A. M. \& Nachlas, M. M. (1963). In Methods of Enzymatic Analysis. [H. U. Bergmeyer editor]. New York and London: Academic Press.

Zöllner, N. \& Kirsch, K. (1962). Z. ges. exp. Med. r35, 545 . 